NBSIR $83-2710$

\title{
An Assessment of Ultrasonic Reference Block Calibration Methodology
}

U.S. DEPAFTMENT OF COMMERCE

National Bureau of Standards

National Engineering Laboritory

Center for Manufacturing Engineering

Mecinanical Production Metrology Division

Utrasonic Standards Group

Washington, DC. 20234

June 198?

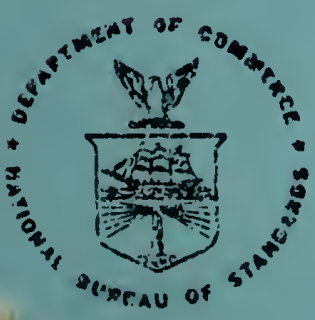

U.S. DEPARTMENT DF COMMERCE

100

.456

$83-2710$

1983

C. 2 

NBSIR $83-2710$

(.)

\section{AN ASSESSMENT OF ULTRASONIC REFERENCE BLOCK CALIBRATION METHODOLOGY}

G. V. Blessing

U.S. DEPARTMENT OF COMMERCE

National Bureau of Standards

National Engineering Laboratory

Center for Manufacturing Engineering

Mechanical Production Metrology Division

Ultrasonic Standards Group

Washington, DC 20234

June 1983

U.S. DEPARTMENT OF COMMERCE, Malcolm Baldrige, Secretary NATIONAL BUREAU OF STANDARDS. Ernest Ambler. Director 
List of Figures . . . . . . . . . . . . . . . . . . . . . . . . 1

List of Tables. . . . . . . . . . . . . . . . . . . . . 2

Abstract. . . . . . . . . . . . . . . . . . . . . . 3

1. Introduction. . . . . . . . . . . . . . . . . . . 4 4

2. Background. . . . . . . . . . . . . . . . . . . . 4

3. Approach. . . . . . . . . . . . . . . . . . . 6

4. Results . . . . . . . . . . . . . . . . . . . . 6

4.1. Block Material. . . . . . . . . . . . . . 6

4.2. Transducer. . . . . . . . . . . . . . . . 9 9

4.3. Pulser/Receiver . . . . . . . . . . . . . . . . . 11

4.4. Primary Reference Standard. . . . . . . . . . . . . 12

4.5. Operator Judgment \& Procedures. . . . . . . . . . . . 13

4.6. Block Geometry. . . . . . . . . . . . . . . . . . 14

5. Recommendations . . . . . . . . . . . . . . . . . . 14

6. Conclusions . . . . . . . . . . . . . . . . . . 16

7. Acknowledgements. . . . . . . . . . . . . . . . . 16

8. References. . . . . . . . . . . . . . . . . . . . . 17

Appendix. . . . . . . . . . . . . . . . . . . . 20 



\section{LIST OF FIGURES}

Figure 1. Illustration of an ultrasonic flat-bottom-hole reference block.

Figure 2. The principal components of an ultrasonic calibration system for reference blocks: the transducer, the pulser/receiver, the primary reference standards, the reference blocks and the immersion tank and yoke system to suspend and manipulate the transducer relative to the targets.

Figure 3. Echo amplitude data as a function of metal-path distance for an anomalous reference block set (diamonds), compared with typical values (solid line).

Figure 4. A continuous profile scan of the back-surface echo amplitude from A) the anomalous block material, and B) the normal block material.

Figure 5. Far-field center axis beam profiles of a ceramic (dashed line) and a quartz transducer (solid line).

Figure 6. Reference-block-echo amplitude data taken with a ceramic transducer (discrete points), relative to that taken with a quartz transducer (solid line), as a function of metal path distance for a No. 5 hole set. Ceramic values using two distinct targets before the application of correction factors (diamonds and triangles), compared to the corrected values (stars) using a block target. 


\section{LIST OF TABLES}

Table 1. Relative echo amplitude responses of a reference block (5-0050) and a steel sphere (5/16-inch diameter) as a function of pulse width.

Table 2. Steel sphere diameters used to set system sensitivity for the respective block hole sizes, according to ASTM El27. 
The state of the art in aluminum ultrasonic reference block calibration practices is reviewed, especially as it has been guided by the recommended practices of ASTM for aluminum blocks. The principal system variables in the calibration procedure are identified, and recommendations for reducing their associated measurement errors are presented. Quantitative evaluations of the limitations to improving measurement precision are made in light of present technology. Suggestions for improving present practices are given, and extensive reference to the relevant technical literature is made.

Key words: ASTM El27; ASTM reference block calibrations; ultrasonic aluminum reference blocks; ultrasonic system calibration; ultrasonic transducer calibration; nondestructive evaluation. 


\section{INTRODUCTION}

Flat-bottom-hole reference blocks have been used as defect artifact standards in ultrasonic nondestructive testing for many years. They were first introduced into an official document of recommended practice in 1958 by the American Society for Testing and Materials (ASTM), where the application was specifically to aluminum alloy blocks [1]1. Whereas the title of that document, "Fabricating and Checking Aluminum Alloy Ultrasonic Standard Reference Blocks," has not changed, its requirements for block acceptance have changed considerably. At its inception, the practice called for a tolerance of $\pm 1 \mathrm{~dB}$ relative to a set of standard tabulated values for echo amplitudes from the flat-bottom-holes. While subsequent efforts were made to improve the original practice, the tolerance has in fact been gradually relaxed to its present level of +2 and $-3 \mathrm{~dB}[2]$.

Recently, the United States Department of Defense, by way of an Army-sponsored project, sought to reduce that tolerance to the original $\pm 1 \mathrm{~dB}$ level in its own applications. For that purpose, the National Bureau of Standards was asked to define the necessary practice and rewrite the appropriate documentation. This report $^{2}$ summarizes the feasibility of doing so, and the requirements involved.

This report is not intended to reflect on the intrinsic value of flat-bottom-holes as artifact standards or as defect simulators. (Refer to the Appendix.) That is, it is not the purpose of this work to develop a better standard with which to enhance flaw assessment. Rather, it is our goal to achieve greater uniformity of measurement results among different laboratories by means of a more precise practice to fabricate and utilize the artifact standards prescribed in ASTM.

\section{BACKGROUND}

In this report, ultrasonic reference blocks refer to a set of aluminum cylinders two inches in diameter, and lengths ranging nominally from one to seven inches. At one end of each cylinder, a flat-bottom-hole of a specific diameter (typically $3 /, 5 /$, or $8 / 64$ inch) is coaxially drilled to a depth of 0.75 inches. Figure 1 illustrates this geometry. With system sensitivity for each hole size defined by the response from a corresponding diameter metal sphere, a calibration is performed by measuring the amplitude of the ultrasonic echoes from the flat-bottom-hole as a function of metal path distance. The originally prescribed tolerance for these echoes, to which we hope to return, was $\pm 1 \mathrm{~dB}$ relative to a set of standard amplitude values.

Two distinct philosophies may be considered for achieving the $\pm 1 \mathrm{~dB}$ objective. With one, a procedure similar to ASTM E127 may be followed wherein each separate laboratory facility would be self-sufficient for its own calibration work. With the

\footnotetext{
I

Numbers in brackets indicate the literature references at the end of this report.

2

Presented, in part, at the 1982 Spring and Fall conferences of the American Society for Nondestructive Testing [3,4].
} 


\section{Ultrasonic Wave Entry Surface}

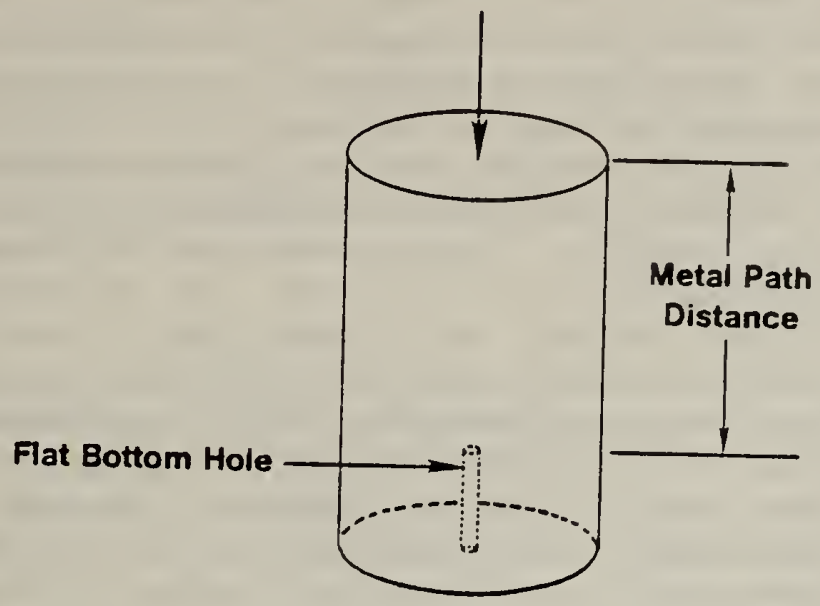

Figure 1 .

Illustration of an ultrasonic flat-bottom-hole reference block

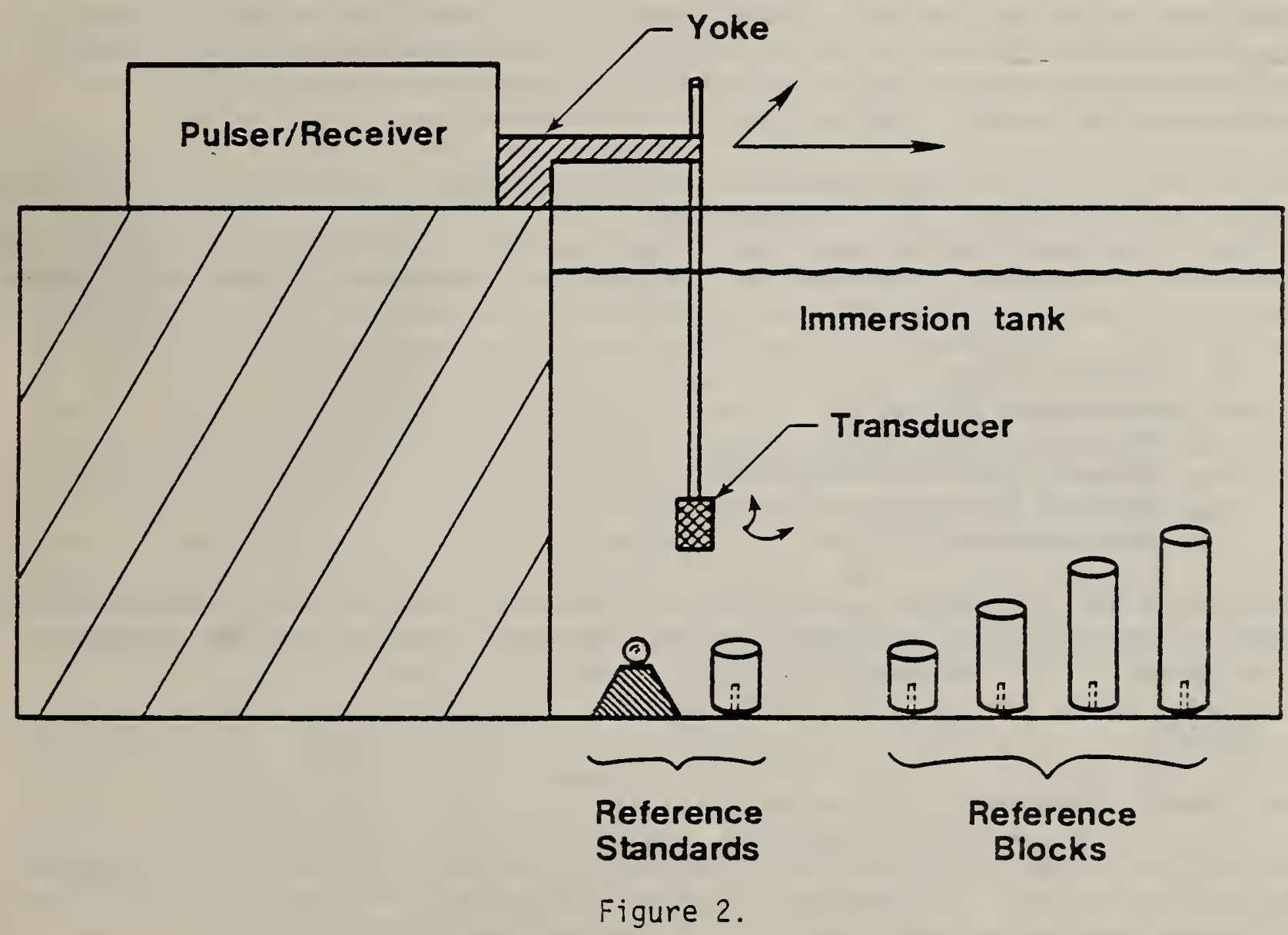

The prinicpal components of an ultrasonic calibration system for reference blocks: the transducer, the puiser/receiver, the primary reference standards, the reference blocks and the immersion tank and yoke system to suspend and manipulate the transducer relative to the targets. 
other, a central calibration facility would evaluate all blocks used in Defense Department work. The principal advantage of the first approach is the independence each field laboratory would have to perform its own calibrations. The principal advantage of the second is to substantially reduce interlaboratory system variables by applying the same instrumentation and detailed procedures to all calibrated blocks. Correction factors could then be applied to correlate with the readings of the central calibration facility. For a comparison of these approaches with other national and international standard practices, see references [5] and [6].

For this work, the first approach was chosen, whereby each individual laboratory facility would perform its own ultrasonic calibration using its own block set purchased directly from the manufacturer. This is the more ambitious approach, requiring greater block and test system uniformity amongst different facilities, but also allows for a large degree of inter-facility flexibility and independence. In either case, it is necessary to explore the detailed system variables to determine the optimum feasibility.

\section{APPROACH}

A review of the literature, supplemented by experimentation in specific areas, was undertaken to define the major system variables. Consideration was limited to liquid-immersion testing, as direct contact techniques were judged not feasible for the desired measurement precision. In direct contact measurements, repeatability error alone far exceeds the desired $\pm 1 \mathrm{~dB}$ tolerance.

The ultrasonic system may be divided into two principal components: the reference blocks to be measured, and the measurement system consisting of the. electronic equipment and ultrasonic transducer. While our goal is to evaluate block variables, to achieve that we must consider the variables of the entire system. For purposes of analysis, the principal system variables were categorized as follows (see Fig. 2):

1. Block Material

2. Ultrasonic Transducer

3. Pulser/Receiver

4. Primary Reference Standards

5. Operator Judgment and Procedures

6. Block Geometry

These principal variables, listed in an approximate order of descending importance, were in turn subdivided and quantitatively analyzed, where possible, for their contribution to net system variability.

4. RESULTS

4.1. Block Material

The block material has proved itself to be a significant variable in the ultrasonic calibration system. The material parameters which may contribute to variations in ultrasonic scattering and, therefore, to variations in the received echo amplitude include texturing, grain size, microporosity, and residual stress. 
Although ASTM E127 recommends specific procedures for processing aluminum bar, the subsequent evaluation of material ultrasonic properties is very limited. Prior to sectioning, ultrasonic waves are propagated diametrically through the extruded or rolled bar, and the material is judged acceptable if the back-scattered waves from within the bar are below a certain level. Prior to hole drilling, no evaluation is made of scattering for wave propagation parallel to the bar axis, which is the wave direction for echo amplitude calibrations.

While the present screening requirements for raw bar material may be inadequate, the difficulty in establishing more precise quantitative criteria becomes apparent with the following considerations. If we arbitrarily decide to limit the contribution of material variations to one-half of the desired $\pm 1.0 \mathrm{~dB}$ net system tolerance, we can easily calculate the maximum allowable variation in ultrasonic attenuation for the bar material. For the 0575 (i.e. 5.75 inch metal path distance) block the 11.5 inch round trip path for the ultrasonic waves results in a $\pm 0.04 \mathrm{~dB} /$ inch restriction in material variation. This would probably be a difficult tolerance to meet in aluminum and would, in any event, certainly be difficult to measure.

In practice, a reasonable approach would be to establish a reference standard for evaluating relative material attenuation;, for example, a long (0575) block with a large (No.8) hole (i.e. 8/64 inch diameter hole). Measuring relative material attenuation (or scattering) by an echo from a flat-bottom-hole serves to evaluate the wave propagation properties of the material in the center region of the block, which is the region of most pertinence for block calibrations. Using a large hole minimizes the effect of fabrication errors on echo response, and provides a greater signal to noise ratio for evaluating the echo amplitude.

An extreme example of material variability was reported in a particular No. 5 hole block set [7]. Figure 3 compares the results on that anomalous set with typical data for acceptable blocks (solid line). Two facts of note are that the anomalous data (a) are greater in amplitude than the standard data, and (b) increase in amplitude for metal path distances greater than two inches, dramatically diverging from the standard data in the case of the longest blocks. The apparent inference from this second observation of a negatively attenuating block set is very difficult to explain, but may be conjectured to be the result of beam focusing due to material texturing. Upon confirming hole size, shape, and depth integrity by means of radiography and block sectioning, this hypothesis was tested by ultrasonically scanning the 0375 block ( 3.75 inch metal path distance) material itself with the hole removed. A continuous-amplitude profile of the back-surface echo amplitude from this specimen is compared with that from a like-sized normal cylinder ${ }^{3}$ in Fig. 4. The signal level of the peak observed in the anomalous cylinder is $4.5 \mathrm{~dB}$ greater than the corresponding level in the normal cylinder, representing an apparent attenuation difference of $0.6 \mathrm{~dB} /$ inch at the center of the blocks. Metallographic studies revealed a finer dendritic cell structure (with little or no cellular substructure) in an anomolous block than in a good block [8]. How this might be related to the observed ultrasonic phenomena is not clear, however.

$\overline{3}$

This normal cylinder was processed from the same bar material as a block set which satisfied the specifications of ASTM E127. 


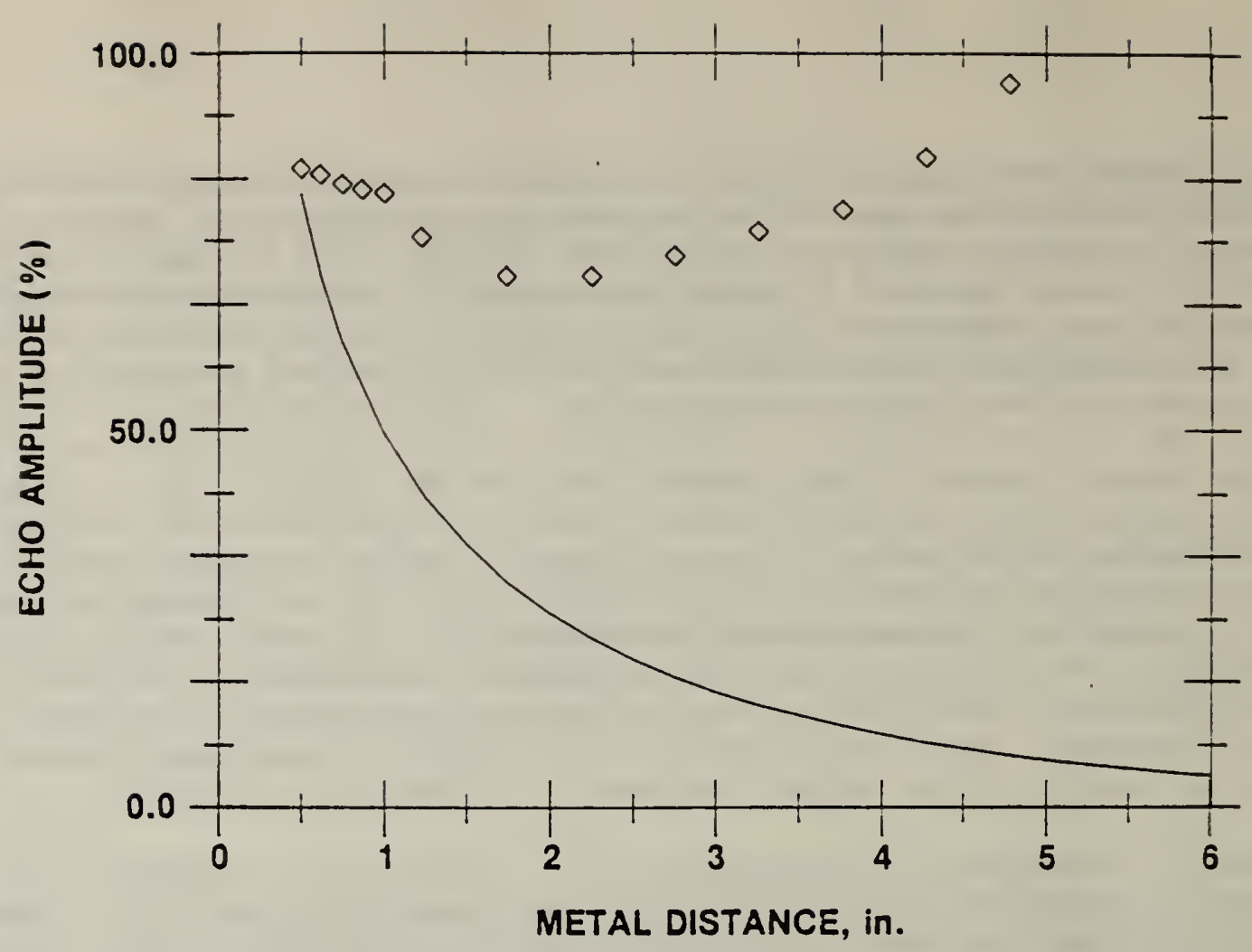

Figure 3.

Echo amplitude data as a function of metal-path distance for an anomalous reference block set (diamonds), compared with typical values (solid line).

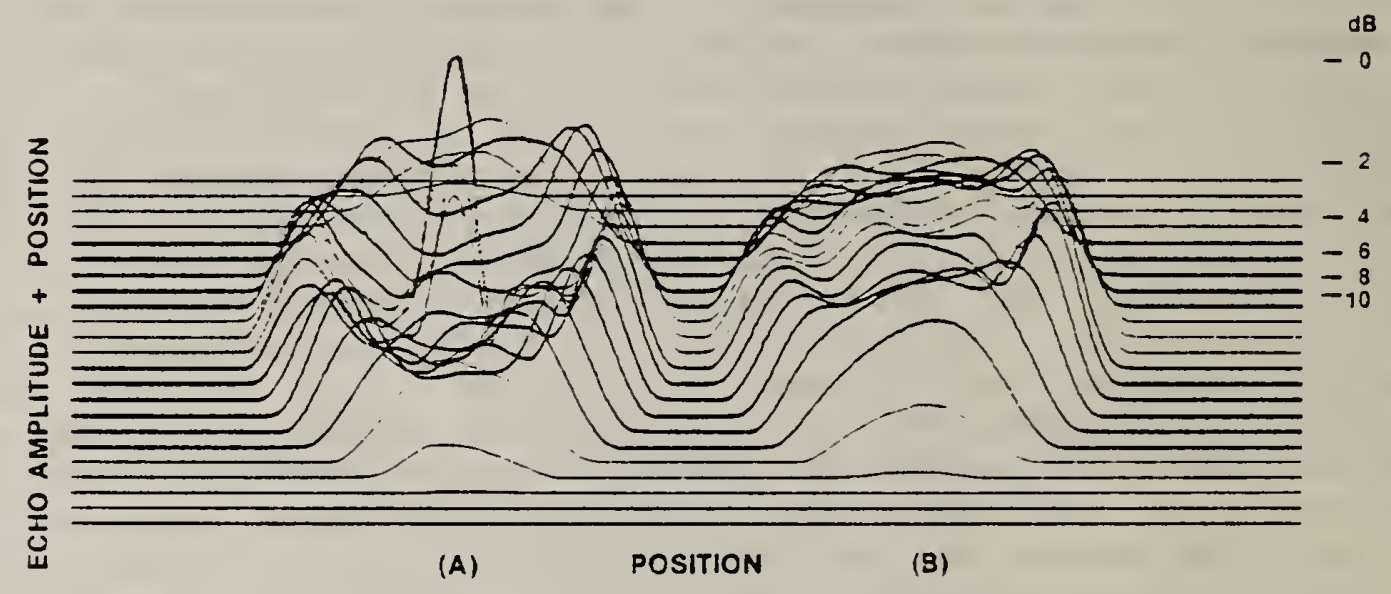

Figure 4 .

A continuous profile scan of the back-surface echo amplitude from $A$ ) the anomalous block material, and B) the normal block material. 
A second significant contribution to the net tolerance of the ultrasonic calibration system is the transducer or search unit. Transducers of supposedly similar or even identical construction have been observed to vary appreciably in their performance characteristics. Substantial research has been undertaken to elucidate the causes $[9-13]$.

The transducer is itself a complex subsystem of the ultrasonic system. The properties of its piezoelectric element vary widely, even for the same piezoelectric material such as ceramic or quartz [14]. Furthermore, its physical structure or housing can have a significant effect on its performance via the damping effects on the piezoelectric crystal. The addition of tuning elements to the transducer package, as is often done to increase sensitivity, causes additional performance variations. Many researchers agree that the following minimum operating parameters should be specified for transducer standardization: center frequency, bandwidth, damping factor, effective area of the piezoelectric element, beam geometry, loop sensitivity (conversion efficiency), and electrical impedance [15-18].

If we restrict ourselves to the use of a specific frequency and material type, e.g. a 5 megahertz quartz crystal, for our pieozoelectric element, (in accordance with the requirements of ASTM El27), some variability still exists. Comparison tests of a set of six quartz transducers, all meeting the transducer specifications of ASTM E127, revealed variations of $t 1 \mathrm{~dB}$ in their echo response from various block sizes [11]. An encouraging aspect to that study, however, was the ability to compensate for the respective transducers' beam pattern differences by means of a farfield echo normalization procedure. This procedure of correction factors was able to reduce the variation in block response observed with the different transducers to a few percent.

In a recent effort to extend this correction factor approach to include ceramic transducers, an empirical study was made to compensate for the response of a given ceramic transducer of a size and fundamental frequency equal to the ASTM E127 quartz standard [4]. The far-field center axis profiles, determined via the echo amplitude from a 0.5-inch diameter spherical steel target, of the two transducers are shown in Fig. 5. The transducers' echo amplitudes were normalized relative to each other by setting the response of each to $80 \%$ of full scale reading at their respective $Y_{0}^{+}$ points. Correction factors were then calculated to raise the ceramic readings to match those of the quartz transducer. Applying this approach to reference block calibrations failed in one application, but proved successful in another. In the one application, initial system sensitivity was defined by the echo from a $5 / 16$ inch diameter steel sphere according to ASTM E127. Applying the correction factors determined from the data of Fig. 5, however, resulted in severely overcompensating for the ceramic transducers' lower echo values. In the other application, initial system sensitivity was defined by the echo from a No. 5-0050 reference block. (The sensitivity setting for the quartz transducer was the same for both targets.) In this case, applying the same correction factors resulted in good agreement with the quartz transducer data, as shown in Fig. 6 . 


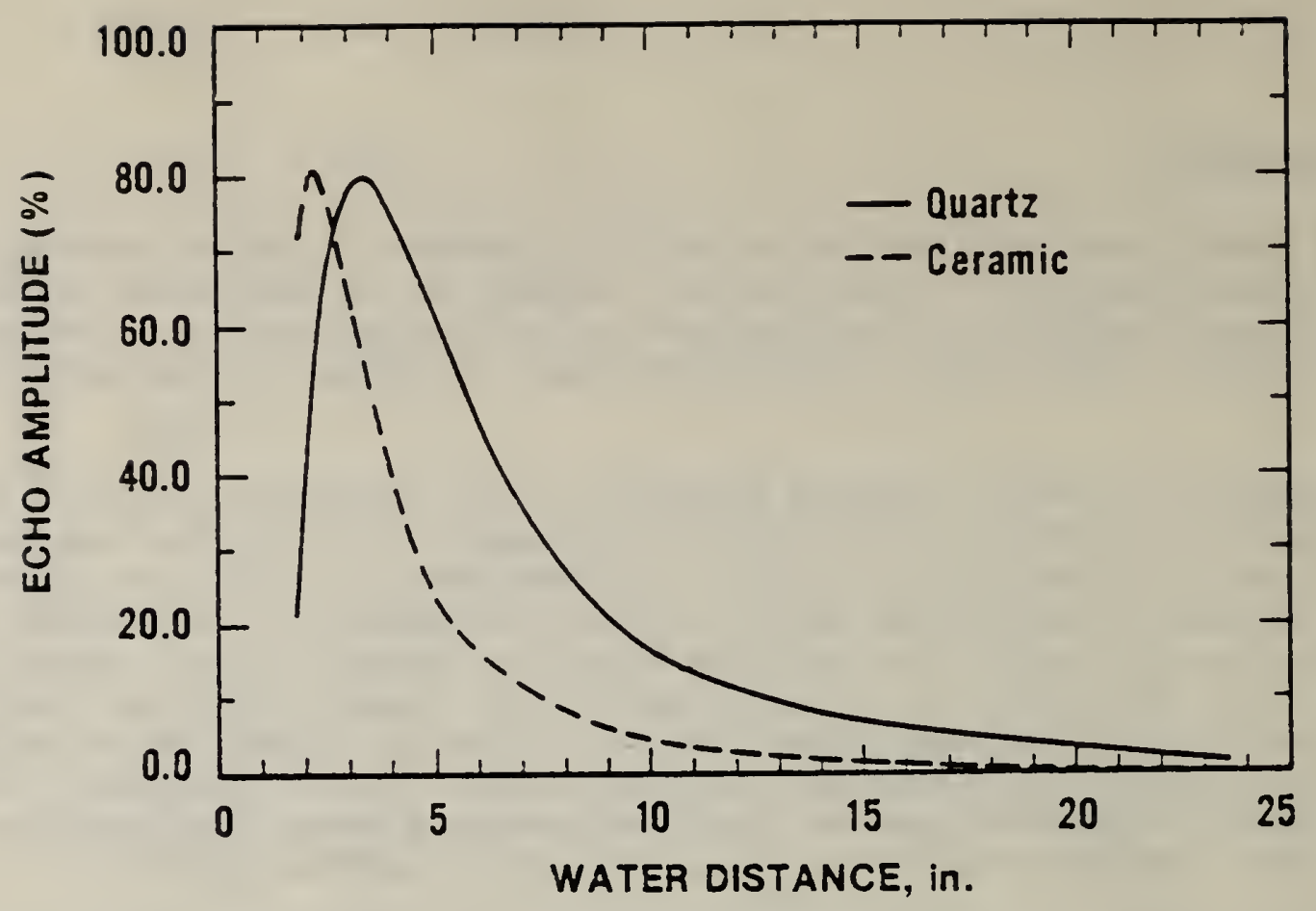

Figure 5.

Far-field center axis beam profiles of a ceramic (dashed line) and a quartz transducer (solid line).

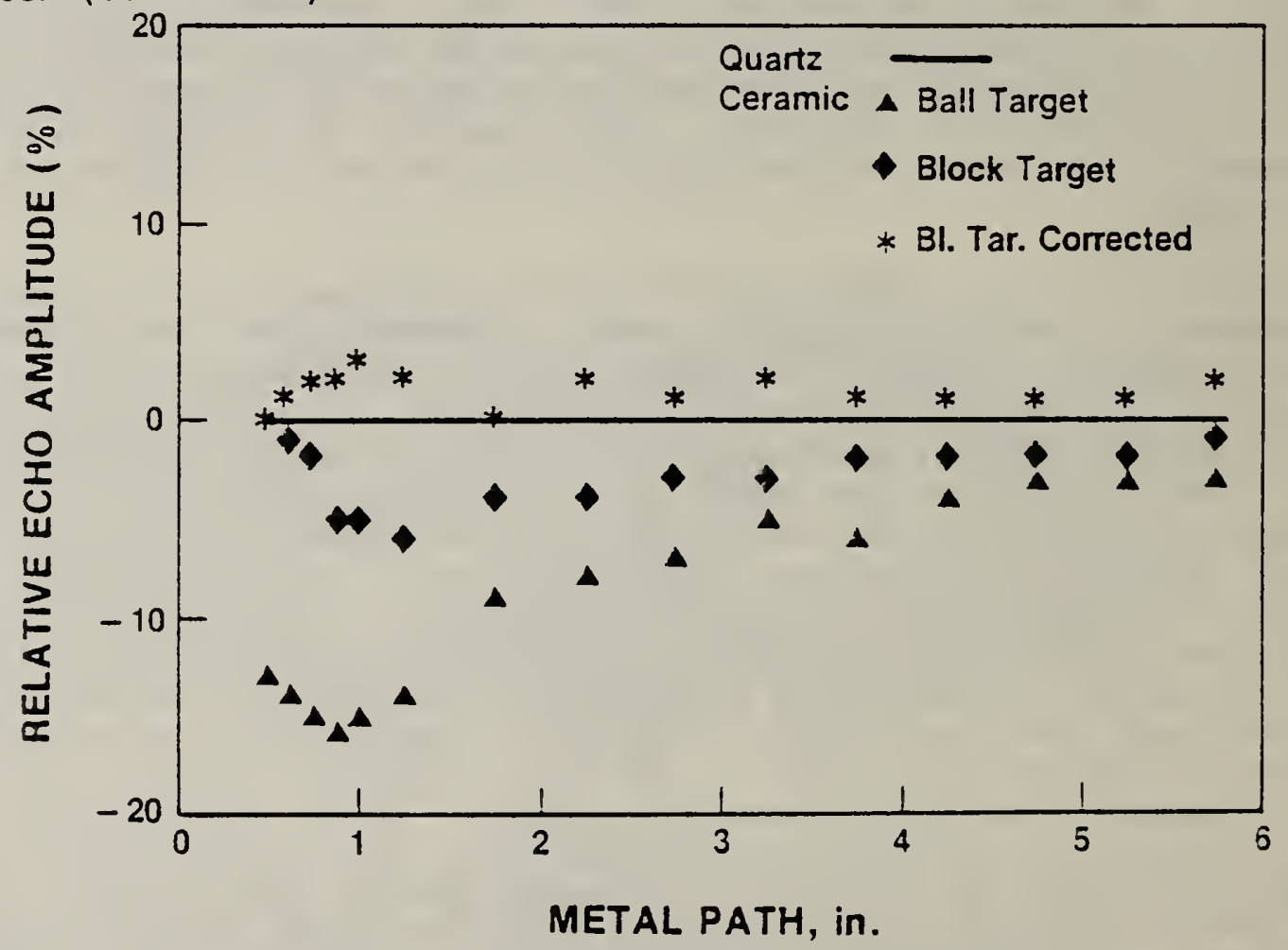

Figure 6.

Reference-block-echo amplitude data taken with a ceramic transducer (discrete points), relative to that taken with a quartz transducer (solid line), as a function of metal path distance for a No. 5 hole set. Ceramic values using two distinct targets before the application of correction factors (diamonds and triangles), compared to the corrected values (stars) using a block target. 
A surprising feature to be noted in Fig. 6 is the improvement of the uncorrected ceramic data taken with initial sensitivity determined by the block target (diamonds), over that taken with sensitivity determined by the spherical target (triangles). While the subsequent application of correction factors (stars) enhances the agreement with the quartz data (horizontal line), a very significant factor for improving the agreement between the two transducers' data appears to be the target used to set system sensitivity [19]. Apparently, the spherical target interrogates features of the ultrasonic beam that are distinctive from those interrogated by a flat-bottom-hole in metal and, therefore, the relative echo difference between the two targets does not transfer proportionately when setting system sensitivity with different transducers. This is attributed principally to the following two factors: (1) target geometry differences-spherical versus flat, and (2) refraction of the ultrasonic wave at the water-metal interface upon entering and exiting the block.

In contrast with this purely empirical approach, a combination theoretic-empiric approach has been recommended by some researches $[12,20,21]$ to develop a standard transducer. With this approach, any transducer becomes a "standard" transducer by having its electro-mechanical transfer function, determined. The approach is to excite the transducer with a known voltage and current pulse, measure the voltage and current of the received echo signal from a known target, and having established the propagation losses between target and transducer, to deconvolve the transfer function. A crucial requirement of this approach is that the target be known, i.e., possess a theoretical solution for its scattering profile. The implementation of this approach will require the development of sophisticated computer sof tware to effectively handle the deconvolution process.

\subsection{Pulser/Receiver}

The electronic pulser used to drive the transducer, and the receiver used to amplify the target echoes, comprise the principal electronic components in the ultrasonic calibration system. Pulse width and shape variations, together with receiver nonlinearity, can substantially affect system performance [19]. Specifically, RF pulse width variations have been observed to cause echo amplitude changes on the order of one $\mathrm{dB}$ (refer to Table 1 in Section 4.4). While such behavior is usually ascribed to changes in the spectral content of the pulsed wave form, and the scatterers' distinctive frequency dependent responses to that pulse [13, 22, 23], mode conversion subtleties may also be playing a significant role [24].

It is not clear how these pulse variables may be controlled in practice, except that at least the pulse width and shape should be kept constant. The NBS does use a constant pulse width for its reference block calibration work, and monitors the shape and spectral content of the output pulse [25]. The ASTM is considering in a draft document, the use of a square wave pulse of specific width related to the wave frequency [18].

The presently allowed tolerance for receiver nonlinearity according to ASTM may be as large as \pm 5 percent of full scale [2]. For lower echo value block readings this results in a very large tolerance. For example, \pm 5 percent out of a 20 percent reading is $\pm 2 \mathrm{~dB}$. Present equipment design should permit a requirement of \pm 1 percent or $\bar{l}$ ess nonlinearity. 
The primary reference standard used in ASTM El27 for initializing system sensitivity is the echo from a spherical steel target (i.e., ball bearings) of a specific diameter depending on the block hole size. The difficulty in obtaining reproducible results with this approach has apparently been due to differences in transducer response to spherical and flat-bottom-hole reflectors, according to the arguments presented above. This means that the amplitude ratio for the responses of different transducers from a spherical target may not be the same as those from a flat-bottom-hole. Possible solutions to this problem may be (1) keeping the transducer constant (or compensating for transducer differences), (2) using a different target, or (3) substituting an electronic source for the target echo. The difficulty of the first approach was discussed above. A discussion of the other two approaches follows.

With regard to the second approach, the effect of pulse width on the two targets' sensitivities to beam characteristics may be exemplified by the data of Table 1 . The receiver gain was adjusted to keep the echo amplitude from a 5-0050 reference block constant at 80 percent of full scale for three discrete settings of pulse width, all of which allowed for ample resolution of the hole echo. The resultant one $\mathrm{dB}$ variation (from minimum to maximum pulse width) in the spherical target echo demonstrates a difference in sensitivity to the two targets which clearly is not desirable in block calibration. Results like these have led to the conclusion that the flat-bottom-hole provides a better primary reference standard for purposes of block calibration than does the steel sphere $[4,7]$.

Table 1. Relative echo amplitude responses of a referecnce block (5-0050) and a steel sphere (5/16 inch diameter) as a function of pulse width.

\begin{tabular}{lcc}
$\begin{array}{l}\text { Pulse } \\
\text { Width }\end{array}$ & $\begin{array}{c}\text { Reference } \\
\text { Block }\end{array}$ & $\begin{array}{r}\text { Steel } \\
\text { Sphere }\end{array}$ \\
\hline Min. & 80.0 & 76.4 \\
Med. & 80.0 & 81.3 \\
Max. & 80.0 & 85.0
\end{tabular}

With regard to the third approach, various attempts to achieve reproducible results by substituting an electronic source for the echo signal have not been very successful. Some of the original work in this area was performed by the Navy to develop an "Electronic Test Block" [26]. More recently, digital circuitry was applied to semi-automate and computerize system sensitivity initialization [27] with a similar scheme, but proved to be inherently limited by coupling variations between the transducer and the standard signal source. 
We add here an important note regarding the inconsistency in the prescription of ASTM E127 for initializing system sensitivity for different hole sizes. For each block hole diameter, a specific diameter target sphere is prescribed in an effort to normalize the echo data from different hole sizes to one set of calibration values. The prescribed sphere diameter for each hole size is given in Table 2 . Since echo amplitude is proportional to the hole diameter squared $[28,29]$ and directly proportional to the sphere diameter [29], the ratio of hole diameters squared should be equal to the ratio of sphere diameters. However, from Table 2 , one finds that relative to the No. 5 hole size, the sensitivity (as determined by a $1 / 8$ inch sphere) for the No. 3 holes will be about ten percent lower, and for the No. 8 holes (as determined by an $11 / 16$ inch sphere) will be about sixteen percent higher.

Table 2. Steel Sphere Diameters Used to Set System Sensitivity for the Respective Block Hole Sizes According to ASTM E127.

$\begin{array}{cccc}\begin{array}{l}\text { FBH } \\ \text { No. }\end{array} & \begin{array}{c}\text { FBH Diameter } \\ \text { (inches) }\end{array} & \begin{array}{c}\text { Sphere Diameter } \\ \text { (inches) }\end{array} & \begin{array}{c}\text { (FBH Dia } \\ \text { Sphere }\end{array} \\ 3 & 3 / 64 & 1 / 8 & 0.90 \\ 5 & 5 / 64 & 5 / 16 & 1.00 \\ 8 & 8 / 64 & 11 / 16 & 1.16\end{array}$

Finally, we note that the use of check standards, for example a specific block or group of blocks (two are used in the NBS procedure for each hole size [25]), would serve several important purposes:

a. Check for proper system alignment and sensitivity initialization;

b. Detect system instability and long term drift;

c. Provide a data base to statistically evaluate measurement repeatability.

\subsection{Operator Judgment and Procedures}

Operator judgment contributes to measurement error in two principal ways: screen readings and alignment procedures. Errors associated with the first may be significantly reduced by replacing video display readings with digital readout. Errors associated with the second may be reduced by means of procedural automation via microprocessor control, but at some cost.

When performing manual calibrations, without the advantage of mechanical automation, at least two and preferably three independent readings of each block are recommended. This not only provides a check for possibly mistaken readings, but also allows for a statistical statement of repeatability. 
A salient consideration for avoiding mistaken block readings is the elimination of air bubbles from the target surfaces and the transducer face. Very small bubbles that may not be noticed in routine procedures can significantly affect echo amplitude, especially if they should form on the primary reference standard when adjusting system sensitivity. For example, a ten percent of full scale reduction in signal, caused by a barely perceptible bubble forming on a 5/16 inch diameter steel sphere, has been observed. The problem is lessened by allowing fresh or recently agitated water to outgas for several days. (Heating the water will enhance outgassing). Backlighting the inspection area, easily done for a tank with transparent walls, greatly enhances the detection of any bubbles that might interfere with the measurements.

\subsection{Block Geometry}

The principal geometric features (Fig. 1) of concern in block fabrication are the flat-bottom-hole and the entry surface. The hole flat, its parallelism with the entry surface, and its diameter are all crucial parameters for block response, as is the roughness of the entry surface itself. In particular, block manufacturers indicate that small deviations from a right angle at the hole-flat perimeter will affect block response. Furthermore, effective quality control of these fabrication parameters requires meticulous machining efforts, and sometimes a trial and error approach.

The effects on echo amplitude have not been well quantified for all these variables. A simple calculation can be-made, however, to determine the effect of hole diameter variation on block response. Since echo amplitude is proportional to flat-bottom-hole area, the ASTM El 27 tolerance of +.0005 inch on the diameter will produce a one to two percent variation in echo ampIitude for a No. 3 size hole. This error will be proportionately less for the larger hole sizes. However, one may question whether this tolerance is, in fact, a feasible machining tolerance for the hole top diameter where a right angle at the perimeter of the hole flat must be met.

\section{RECOMMENDATIONS}

Based on the above studies, specific recommendations to minimize the net tolerance for ultrasonic reference block calibration follow. The categorization is that used for the principal system variables identified above.

1. Block material: Define a (arbitrary) level of ultrasonic material scattering that is consistent with today's manufacturing processes, and as much as possible with the present requirements of ASTM El27, by assigning some value to the echo amplitude from a material standard reference block. An 8-0575 block, fabricated from the candidate material for the block set, would be a consideration. Hopefully, the variation in echo amplitude between any two "identical" blocks, due to material property variations, could be reduced to \pm 5 percent of full scale with this approach. This may require, however, that all extruded rod be taken from the same manufacturing lot and/or that other quality control restrictions be placed on the material. An effective screening for acceptable material should be possible by the use of sampling. 
2. Transducers: A significant improvement for transducer evaluation would be to supplement the requirements of ASTM El27 with a far-field center-axis beam profile analysis. The interplay of target shape (e.g., sphere vs. flat-bottom-hole) with this analysis must be carefully considered. Based on the empirical approach described above, and the discussion that followed, a tolerance of +3 percent of full scale in block response should be realizable for this variable. To extend this practice to include other piezoelectric material types such as ceramic may be feasible using a correction factor approach, but would require further study.

3. Pulser/Receiver: The effects of variations between pulser/receiver units can be minimized by using pulses of the same shape and amplitude (and, therefore, spectral content) to drive the transducer. If, in addition, the receiver linearity were kept within \pm 1 percent of full scale, it should be feasible that the combined pulser and receive $\bar{r}$ stay within +4 percent of full scale bounds for reference block measurements.

4. Primary Reference Standard: The use of a spherical steel target as the primary reference standard is considered problematic. A more suitable target, sensitive to the same beam characteristics as flat-bottom-hole blocks, and one that would be reproducible, is not known, however. In lieu of that ideal target, it is recommended that each laboratory performing calibrations identify a specific 0050 block with controlled or known characteristics for use at least as a check standard.

Since the variations in system response due to the primary reference standard used can be eliminated by using identical transducers and driving pulses, assigning an additional tolerance to this variable would be duplicative. However, it should be borne in mind that in practice identical transducers and pulsers are not the case, and the search for a more suitable target to minimize the effects of these and other system variables should be made.

Finally, the source of systematic error attributable to ASTM El27, as it is presently written, should be recognized. The discrepancy between the spherical target diameter ratios and the hole area ratios requires that the tabular data of recommended block responses be corrected for different hole sizes.

5. Operator Judgment and Procedures: By eliminating screen reading judgment errors with digital readout of signal amplitude, the principal operator-dependent variations would be limited to alignment errors. The detection of bubbles on the transducer and/or block surface, a potential source of large error, is greatly facilitated by back-lighting an immersion tank having transparent siding. Finally, to minimize operator-dependent errors, all reported amplitude values should be an average of three repeated measurements; and a difference of more than two percent of full scale within these three measurements should raise a caution flag, and be investigated.

These factors combined should not contribute more than +1 percent of full scale to system tolerance for the first half of the calibration curve, and \pm 2 percent for the second half.

6. Block Geometry: So long as reference blocks are fabricated by hole drilling, possible variations of \pm 3 percent in echo amplitude due to this process will have 
to be ascribed to the smaller diameter hole sizes. This assumes the machining tolerance discussed above to be feasible, and includes variations due to the other principal geometrical features of parallelism and front surface roughness. Variations in the larger holes (No. 5 and No. 8) will be proportionally less.

\section{CONCLUSIONS}

By assuming a random accumulation of the six source errors listed above, it is reasonable to develop a specification with a net system tolerance equal to the square root of the sum of their squares. Using the individual tolerance values identified and/or estimated there, the net system tolerance could be expected to meet a value of plus or minus eight percent of full scale.

In decibels, a figure of +8 percent of full scale is less than $+1 \mathrm{~dB}$ for the shortest blocks, but scales up to nearly $\pm 3 \mathrm{~dB}$ for the longest b̄locks. We note that the largest contribution to this tolerance is that due to the estimated material variation, which may in practice be significantly less. It is ironic that a given percent of full scale tolerance expressed in decibels imposes the most stringent requirements on the longest blocks, which are most prone to ultrasonic response variati ns to begin with. In light of these analyses, therefore, \pm \pm 1 dB tolerance using the approach of ASTM El27 may not be feasible for all blocks.

\section{ACKNOWLEDGEMENTS}

The partial support of the Army Materials and Mechanics Research Center, Watertown, MA, is gratefully acknowledged. The laboratory help of Mr. Jimmy James, an NBS Cooperative Student from Prairie View A \& $M$ in Texas, is also gratefully acknowledged. 


\section{REFERENCES}

1. Tentative recommended practice for fabricating and checking aluminum alloy ultrasonic standard reference blocks, E127-58T, in Annual book of ASTM standards, part 3. Philadelphia, Pennsylvania: American Sociecy for Testing and Materials; 1958.

2. Standard practice for fabricating and checking aluminum alloy ultrasonic standard reference blocks, E127-81, in Annual book of ASTM standards, part 11. Philadelphia, Pennsylvania: American Society for Testing and Materials; 1982.

3. Blessing, G.V.; Eitzen, D.G. Ultrasonic standard reference blocks - what future?, in 1982 paper summaries of the ASNT national conference; 1982 March 22-25; Boston, Massachusetts. Columbus, Ohio: American Society for Nondestructive Testing; 1982. 9-12.

4. Blessing, G.V.; Eitzen D.G. Variables affecting ultrasonic reference block calibration, in 1982 October 4-7; Pittsburgh, Pennsylvania. Columbus, Ohio: American Society for Nondestructive Testing; 1982. 287-291.

5. Golan, S. A comparison of American and European ultrasonic testing standards. Nat. Bur. Stand. (U.S.) NBSIR 79-1790; 1979 June. 74 p.

6. Millman, I. An improved facility for the calibration of aluminum alloy ultrasonic reference blocks. Report A.Q.D./N.D.T. 1369. A.Q.D. Laboratories (U.K.); 1973. 29 p.

7. Eitzen, D.G.; Sushinsky, G.F.; Chwirut, D.J.; Bechtoldt, C.J.; Ruff, A.W. Improved ultrasonic standard reference blocks. Nat. Bur. Stand. (U.S.) NBSIR 75-685; 1975 April.

8. Hughes, R. Private communication (to G. Blessing). Richmond, Virginia; Reynolds Metal Co.; 1983 February.

9. Bredael, I. Characterization of ultrasonic transducers, chapter 5 in Research techniques in nondestructive testing, vol. III, R.S. Sharpe, ed. New York, New York: Academic Press; 1977. 175-215.

10. Papadakis, E.P. Ultrasonic transducer evaluation in five "domains": time, space, frequency, surface motion, and theory, in 1977 ultrasonics symposium proceedings. Paper no. 77CH1264-1 SU; 1977. 104-112.

11. Chwirut, D.J.; Boswell, G.D. The evaluation of search units used for ultrasonic reference block calibrations. Nat. Bur. Stand. (U.S.) NBSIR 78-1454; 1978 February. 29 p.

12. Sachse, W.; Hsu, N.N. Ultrasonic transducers for materials testing and their characterization, chapter 4 in Physical Acoustics, vol. XIV, W.P. Mason, ed. New York, New York: Academic Press; 1979. 277-406.

13. Silk, M.G. Predictions of the effect of some constructional variables on the performance of ultrasonic transducers. Ultrason. 21(1): 27-33; 1983 January. 
14. Kim, B.S. Material property measurements of PZT-5A-type piezoelectric ceramics. Matls. Eval. 40(10): 1180-1183; 1982 October.

15. McElroy, J.T. Search unit characterization, in Nondestructive testing standards - a review, H. Berger, ed.; 1976 May 19-21; Gaithersburg, Maryland. ASTM Special Pub. 624. Philadelphia, Pennsylvania: American Society for Testing and Materials; 1977 June. 133-145.

16. Borloo, E.E.; Jehenson, P. Proposal of a characterization sheet for ultrasonic transducers, in Proceedings of the first international symposium on ultrasonic materials characterization, H. Berger, M. Linzer, eds.; 1978 June 7-9; Gaithersburg, Maryland. Nat. Bur. Stand. (U.S.) Special Pub. 595; 1980 November. 617-626.

17. Hegeon, K.; Burkhardt, G.L.; Teller, C.M. Ultrasonic transducer performance requirements -- phase III. Final engineering report. Southwest Research Institute Project No. 15-5711. San Antonio, Texas; Southwest Research Institute; 1981 August. 38 p.

18. Draft recommended practice for evaluation of ultrasonic search units, ASTM E-07-06-09-82-1-2. Philadelphia, Pennsylvania: American Society for Testing and Materials; 1982 August. 37 p.

19. Chwirut, D.J. Recent improvements to the ASTM-type ultrasonic reference block system. Nat. Bur. Stand. (U.S.) NBSIR 79-1742; 1979 April. 53 p.

20. Tittmann, B.R.; Thompson, D.0.; Thompson, R.B. Standards for quantitative nondestructive examination, in Nondestructive testing standards - a review, $\mathrm{H}$. Berger, ed.; 1976 May 19-21; Gaithersburg, Maryland. ASTM Special Pub. 624. Philadelphia, Pennsylvania: American Society for Testing and Materials; 1977 June. 295-311.

21. Cleveland, D.; Mucciardi, A.N. Frequency domain methods for reducing transducer variability. J. Nondestruc. Eval. 1(2): 101-109; 1980 June.

22. Gaunnard, G.C.; Uberall, H. RST analysis of monostatic and bistatic acoustic echoes from an elastic sphere. J. Acoust: Soc. Am. 73(1): 1-12; 1983 January.

23. Crostack, H.A.; Oppermann, W. Determination of the optimum centre frequency for ultrasonic testing of sound-scattering materials. Ultrason. 21(1): 19-26; 1983 January.

24. Maze, G.; Ripoche, J. Visualization of acoustic scattering by elastic cylinders at low ka . J. Acoust. Soc. Am. 73(1): 41-43; 1983 January.

25. Chwirut, D.J.; Sushinsky, G.F.; Eltzen, D.G. Procedures for the calibration of ASTM El27-type ultrasonic reference blocks. Nat. Bur. Stand. (U.S.) Tech. Note 924; 1976 September. 44 p.

26. Chaskelis, H. An acoustic transponder for calibrating ultrasonic equipment. Naval Research Laboratory (U.S.) Memorandum 3552; 1977 October. 10 p.

27. Sproat, W.H. New ultrasonic standard design criteria. U.S. Air Force Report AFWAL-TR-80-4198; 1981 January. 39 p. 
28. Keller, J.B. Diffraction by an aperture. J. Appl. Phys. 28(43): 426-444; 1957 April.

29. Ermolov, I.N. The reflection of ultrasonic waves from targets of simple geometry. Non-Destruc. Test. 5: 87-91; 1972.

30. Birnbaum, G.; Eitzen, D.G. An appraisal of current and future needs in ultrasonic NDE standards. Nat. Bur. Stand. (U.S.) NBSIR 79-1907; 1979 October. 79 p. 


\section{APPENDIX}

We stated it was not the purpose of this report to judge the flat-bottom-hole reference standard per se. Here, however, we mention those qualities which an ideal calibration standard might possess [30]:

1. Fabrication reproducibility

2. Measurement reproducibility

3. Primary standard functioning to calibrate secondary or field type standards

4. Theoretical traceability

5. Flaw simulation

6. Ease in setting system sensitivity

7. Performance for equipment evaluation

8. Ease of automation

9. Low cost

10. Compatibility with existing standard.

Perhaps the most frequently discussed limitation of the flat-bottom-hole standard relative to the above criteria is its shortcoming in simulating real defects. While this criticism may be valid, it should be recognized that it is only one of many criteria to judge a standard by, and for many purposes may not be the most important. It should also be pointed out that the original rationale for choosing the flat-bottom-hole was that it best simulated the more critical flaws - lamellar defects and cracks, whereas other artifact candidates such as spheres and cylinders best simulate relatively benign pores. Hopefully, an improved general purpose primary reference standard is forthcoming, but until it does, flat-botton-hole fabrication and calibration procedures deserve optimization. 
NBS-114A (REV. 2-8C)

U.S. DEPT. OF COMM

BIBLIOGRAPHIC DATA

SHEET (See in structions)

1. PUBLICATION OR REPORT NO.

NBSIR $83-2710$
2. Performing Organ. Report Nod 737.03
3. Publication Date

June 1983

4. TITLE AND SUBTITLE

An Assessment of U1trasonic Reference Block Calibration Methodology

5. AUTHOR(S)

G.V. Blessing

6. PERFORMING ORGANIZATION (If joint or other than NBS, see instructions)

7. Contract Grant No.

NATIONAL BUREAU OF STANDARDS

DEPARTMENT OF COMMERCE

WASHINGTON, D.C. 20234

8. Type of Report \& Period Covered

Final

9. SPONSORING ORGANIZATION NATME ANO COMPLETE ADORESS (Street, City. Stute, ZIP)

10. SUPPLEMENTARY NOTES

Document describes a computer program; SF-185, FIPS Software Summary, is attached.

11. ABSTRACT (A 200-word or less factual summary of most significant information. If document includes a significant bibliogrophy or literature survey. mention it here)

The state of the art in aluminum ultrasonic reference block calibration practices is reviewed, especially as it has been guided by the recommended practices of ASTM for aluminum blocks. The principal system variables in the calibration procedure are identified, and recommendations for reducing their associated measurement errors are made. Quantitative evaluations of the limitations to improving measurement precision are made in light of present technology. Suggestions for improving present practices are made, and extensive reference to the relevant technical literature is made.

12. KEY WORDS (Six to twelve entries; alphabetical order; capitalize only proper names; and separate key words by semicolons) ASTM E127; ASIM reference block calibrations; ultrasonic aluminum reference blocks; ultrasonic system calibration; ultrasonic transducer calibration.

\section{AVAILABILITY}

X Unlimited

For Official Distribution. Do Not Release to NTIS

Order From Superintendent of Documents, U.S. Government Printing Office, Washington, D.C. 20402.

X] Order From National Technical Information Service (NTIS), Springfield, VA. 22161
14. NO. OF

PRINTED PAGES

23

15. Price

$\$ 7.00$ 

